\title{
Contaminación del Lago de Tota y Modelos Biológicos para estudios de Genotoxicidad
}

\author{
Tota Lake Pollution and Biological \\ Models for Genotoxicity Studies
}

Fecha de Recepción: 26.02.2020

Fecha de Aceptación: 10.05.2020

Doi: https://doi.org/10.19053/01217488.v11.n2.2020.11467

\author{
Diego F. Jaramillo-García ${ }^{a}$ \\ Natalia Rodríguez-Sosa ${ }^{b}$ \\ Marleny Salazar-Salazarc \\ Carlos A. Hurtado-Montaño ${ }^{\mathrm{d}}$ \\ Milena Rondón-Lagos ${ }^{\mathrm{e} *}$
}

\section{Resumen}

El Lago de Tota es una fuente hídrica de gran importancia a nivel regional y nacional dado su valor ambiental y económico, este último representado por actividades agrícolas, pecuarias y piscícolas. Estas actividades han contribuido a la contaminación observada en la actualidad, siendo esta una problemática ambiental en constante ascenso, donde la salud, el desarrollo de las comunidades y los procesos ecológicos, se han visto afectados. De hecho, el Lago de Tota ha sido catalogado como uno de los ecosistemas más amenazados del planeta por la red mundial de humedales. A pesar de la problemática ambiental que representa la contaminación del Lago, son muy pocos los estudios que indagan acerca del daño genético generado por la exposición a los agentes tóxicos presentes en esta cuenca. A este respecto un modelo biológico óptimo para estudios de genotoxicidad lo constituye el pez cebra, dada su alta homología genética con el humano, así como su capacidad de regeneración, adaptación y respuesta inmune ante altas concentraciones de compuestos químicos como los plaguicidas. Esta revisión se enfoca en reportes recientes sobre la contaminación del Lago de Tota y en el uso de modelos biológicos para estudios de genotoxicidad.

Palabras Clave: Contaminación, Daño citotóxico, Daño genotóxico, Lago de Tota, Modelo biológico, Pez cebra.

\begin{abstract}
Tota Lake is a water source of great importance at a regional and national level given its environmental and economic value, the latter represented by agricultural, livestock and fish farming activities. These activities have contributed to the contamination observed at present, being an environmental problem in constant rise, where the health, the development of the communities and the ecological processes have been affected. In fact, Lake Tota has been classified as one of the most threatened ecosystems on the planet by the global network of wetlands. Despite the environmental problems posed by the contamination of the Lake, there are very few studies that investigate the genetic damage generated by exposure to the toxic agents present in this basin. In this regard, an optimal biological model for genotoxicity studies is the zebrafish, given its high genetic homology with humans, as well as its capacity for regeneration, adaptation and immune
\end{abstract}

\footnotetext{
a Estudiante de Biología. Octavo semestre, Grupo de Investigación en Ciencias Biomédicas-UPTC, Escuela de Ciencias Biológicas. Universidad Pedagógica y Tecnológica de Colombia, Tunja, Colombia.

b Estudiante de Biología. Noveno semestre, Grupo de Investigación en Ciencias Biomédicas-UPTC, Escuela de Ciencias Biológicas. Universidad Pedagógica y Tecnológica de Colombia, Tunja, Colombia.

PhD. Programa de Licenciatura en Biología y Educación Ambiental, Facultad de Educación, Universidad del Quindío, Colombia.

Estudiante. Programa de Licenciatura en Biología y Educación Ambiental, Facultad de Educación, Universidad del Quindío, Colombia.

PhD. Escuela de Ciencias Biológicas, Universidad Pedagógica y Tecnológica de Colombia, Tunja, Colombia

Autor de correspondencia: sandra.rondon01@uptc.edu.co
} 
response to high concentrations of chemical compounds such as pesticides. This review focuses on recent reports on Tota Lake contamination and the use of biological models for genotoxicity studies.

Keywords: Biological model, Contamination, Cytotoxic damage, Genotoxic damage, Lake Tota, Zebra fish.

\section{INTRODUCCIÓN}

El lago de Tota es catalogado como la cuenca con mayor extensión en el país y la segunda en Suramérica. Se encuentra ubicado en el Departamento de Boyacá específicamente entre los municipios de Aquitania, Tota y Cuítiva [1]. Esta cuenca hidrográfica se caracteriza por presentar servicios ecosistémicos de gran trascendencia para la población, entre ellos se destaca: el abastecimiento de agua para el consumo, actividades productivas e industriales y el aprovisionamiento de alimentos [2]. Actualmente es posible evidenciar una serie de problemáticas ambientales que repercuten en la funcionalidad del Lago y, en consecuencia, en las poblaciones que allí habitan. Dentro de las principales fuentes de contaminación del Lago se encuentran la escorrentía de agentes químicos (plaguicidas) empleados en los cultivos de la zona, especialmente de cebolla larga (Allium fistulosum) [1], eutrofización que produce el deterioro de la calidad del agua y las constantes fumigaciones [3].

El uso persistente de plaguicidas se constituye como un grave problema de salud pública a nivel mundial, debido a la morbilidad y mortalidad que estos agentes pueden causar. Dado que los plaguicidas son sustancias que se han empleado para prevenir, destruir, repeler o mitigar plagas tanto en la agricultura como en la lucha contra vectores, su uso ha traído beneficios, pero también ha generado riesgos para el hombre, los animales y el ambiente [4]. Considerando lo anterior, las actividades agroindustriales representan un grave problema de intoxicación con 8245 intoxicaciones reportadas en el año 2013, seguido por 9214 en 2014 y 8732 casos para el 2015 [5].

Sin embargo, a pesar de la problemática ambiental que representa la contaminación del Lago de Tota, son muy pocos los estudios que reportan los efectos nocivos en la salud tanto humana como animal, por lo que resulta indispensable indagar acerca del daño celular y genético que se podría generar por el consumo y exposición a los agentes tóxicos y químicos presentes en esta cuenca. A este respecto, un modelo biológico óptimo para estudios de genotoxicidad y toxicidad lo constituye el pez cebra, modelo que ha adquirido gran importancia en los últimos años dada su alta homología genética con el ser humano, así como su capacidad de regeneración, adaptación y respuesta inmune ante altas concentraciones de químicos como Arsénico, Plomo y glifosato. El objetivo de esta revisión es evidenciar los estudios realizados hasta la fecha alrededor de la contaminación del Lago de Tota, así como los modelos biológicos propuestos para estudiar los efectos nocivos de tal contaminación en las poblaciones humanas y animales.

\section{LAGO DE TOTA}

El Lago de Tota está ubicado al oriente del departamento de Boyacá, en la cordillera oriental de los Andes Colombianos. Las cuencas hidrográficas que surten al lago se encuentran en jurisdicción de los municipios de Aquitania, Tota y Cuítiva [6]. La cuenca cuenta con una extensión de $201 \mathrm{~km}^{2}$ y el Lago abarca $60 \mathrm{~km}^{2}$ aproximadamente [7], por lo tanto, Tota es catalogado como el segundo lago más grande de Latinoamérica después del Titicaca [8]. El aporte del Lago de Tota resulta bastante representativo y de gran importancia para todos los niveles de organización biológica que allí se encuentran [9], además de ser una fuente de recursos importantes para la economía y el desarrollo municipal, departamental y nacional, los cuales están representados por la actividad agrícola, pecuaria y piscícola allí desarrollada [10].

\subsection{Actividad Agrícola}

Predomina el monocultivo de cebolla larga (Allium fistulosum) con un área sembrada en el municipio de Aquitania de 1210 hectáreas (ha) y una producción de 60500 toneladas en el año 2018 [11]. Mientras que en el municipio de Tota y Cuítiva, la producción de cebolla es de 3000 y 1350 toneladas respectivamente (Figura 1) y se estima que existen alrededor de 2200 cultivadores de este producto en la zona [12]. Además de la cebolla, se realizan cultivos de papa (Solanum phureja), haba (Vicia faba) y arveja (Pisum sativum), y su producción se encuentra distribuida en el anillo de municipios que rodea el Lago incluyendo a Aquitania, Tota y Cuítiva, con una producción de 200, 9000 y 70 toneladas de papa 
respectivamente. En lo que respecta a la producción de haba, la mayor producción se encuentra en el municipio de Tota con 115 toneladas, seguido de Aquitania con 13 toneladas y finalmente, Cuítiva con 5 toneladas. En cuanto a la producción de arveja, Tota produce 187 toneladas, Aquitania 28 toneladas y Cuítiva 14 toneladas [11] (Figura 1).

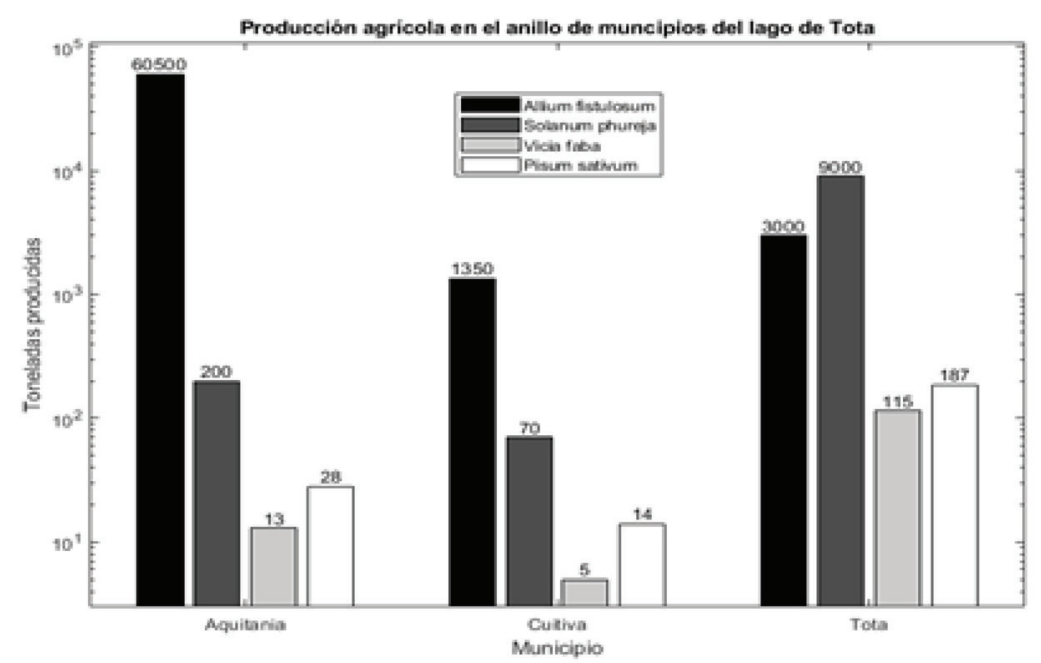

Figura 1. Producción agrícola del anillo de municipios del Lago de Tota. La actividad agrícola desarrollada en Aquitania, Tota y Cuítiva está distribuida en especies vegetales que corresponden a Allium fistulosum, Solanum phureja, Vicia faba y Pisum sativum. Se evidencia predominio del cultivo de cebolla larga en el Municipio de Aquitania, seguido de Cuítiva, mientras que en el Municipio de Tota prevalece la producción de papa criolla. Los datos de producción de dichos cultivos corresponden a la Evaluación Agropecuaria Municipal realizada en el año 2018 [11].

\subsection{Actividad Pecuaria}

En las partes altas del lago se evidencian actividades ganaderas, y según el censo pecuario nacional, el municipio de Aquitania cuenta con
12000 bovinos, 225 caprinos y 2300 ovinos, mientras que en Cuítiva, la población se distribuye en 2050, 150 y 1100 individuos respectivamente. Tota por su parte, cuenta con 5780 bovinos, 250 caprinos y 4800 ovinos [13] (Figura 2).

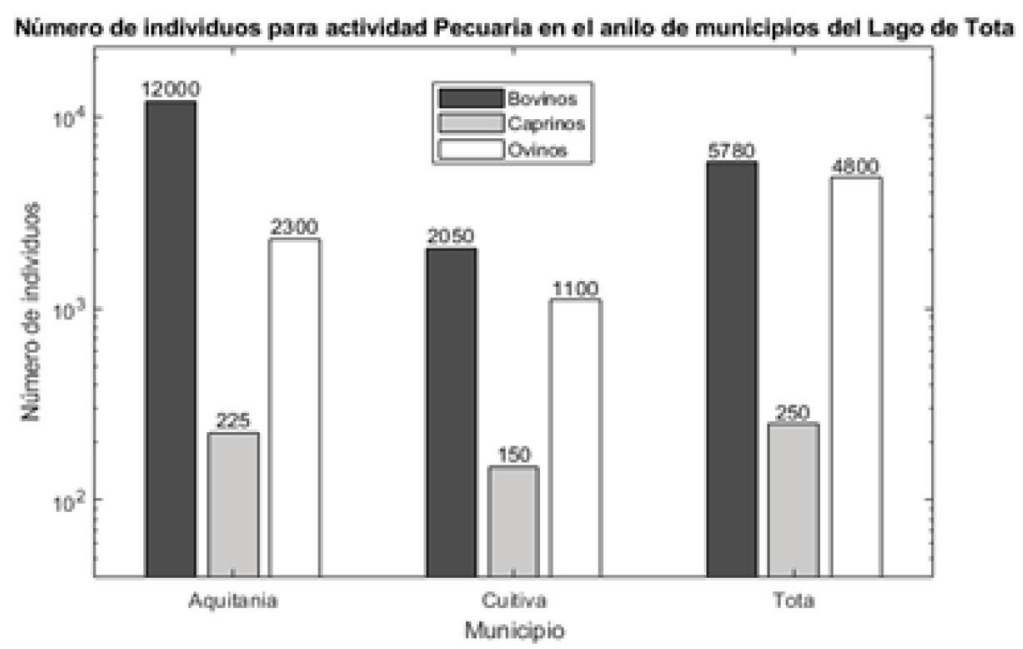

Figura 2. Número de individuos para actividad pecuaria en el anillo de municipios del Lago de Tota. La presencia de poblaciones de bovinos, caprinos y ovinos se encuentra principalmente distribuida en los municipios de Aquitania, Cuítiva y Tota, siendo la población de bovinos y ovinos considerablemente alta especialmente para los municipios de Aquitania y Tota. Los datos corresponden al Censo Pecuario Nacional realizado en el año 2017 [13]. 


\subsection{Actividad Piscícola}

Esta actividad se desarrolla en el municipio de Aquitania con cercanía al lago, allí se observan jaulas flotantes para el cultivo de trucha arco iris (Oncorhynchus mykiss) y se estima que para el año 2018 se obtuvieron alrededor de 6000 individuos en etapa alevina [14], en la cual ya no se necesita el saco vitelino para su alimentación y, por tanto, es considerada una fase en la que los peces pueden ser comercializados y alimentados por medios artificiales [15].

\section{CONTAMINACIÓN DEL LAGO DE TOTA}

A pesar de los beneficios económicos asociados a las prácticas agrícolas desarrolladas alrededor del lago de Tota, estas se han constituido en una problemática ambiental en constante ascenso en los últimos años, donde la salud, el desarrollo de las comunidades y los procesos ecológicos, se han visto afectados. Las principales causas asociadas a esta problemática ambiental incluyen tanto las inadecuadas prácticas agrícolas como la ausencia de información alrededor del manejo de agentes genotóxicos como lo son los plaguicidas. Las fuentes de contaminación son muy variadas y éstas derivan de la utilización de agentes químicos en los cultivos, pérdida de fauna y flora debido a la expansión de terrenos agrícolas, uso inadecuado de las fuentes hídricas, entre otros, causando la pérdida de alrededor de 100 ha de su banco de agua [16]. Lo anterior conllevó a que el lago de Tota haya sido catalogado como uno de los ecosistemas más amenazados del planeta por la Red Mundial de Humedales [17], debido no sólo a las causas anteriormente mencionadas, sino a la disminución de la transparencia en la columna de agua en los últimos quince años [18]. La contaminación del recurso hídrico se debe principalmente al uso de pesticidas y fertilizantes para los diferentes cultivos agrícolas que se desarrollan y que llegan por escorrentía al lago (Figura 3A), vertimiento de agua residuales de los municipios cercanos (Figura 3B), desechos de actividad pecuaria (Figura 3C) así como a la actividad piscícola empleando trucha arcoíris (Figura 3D) [8].
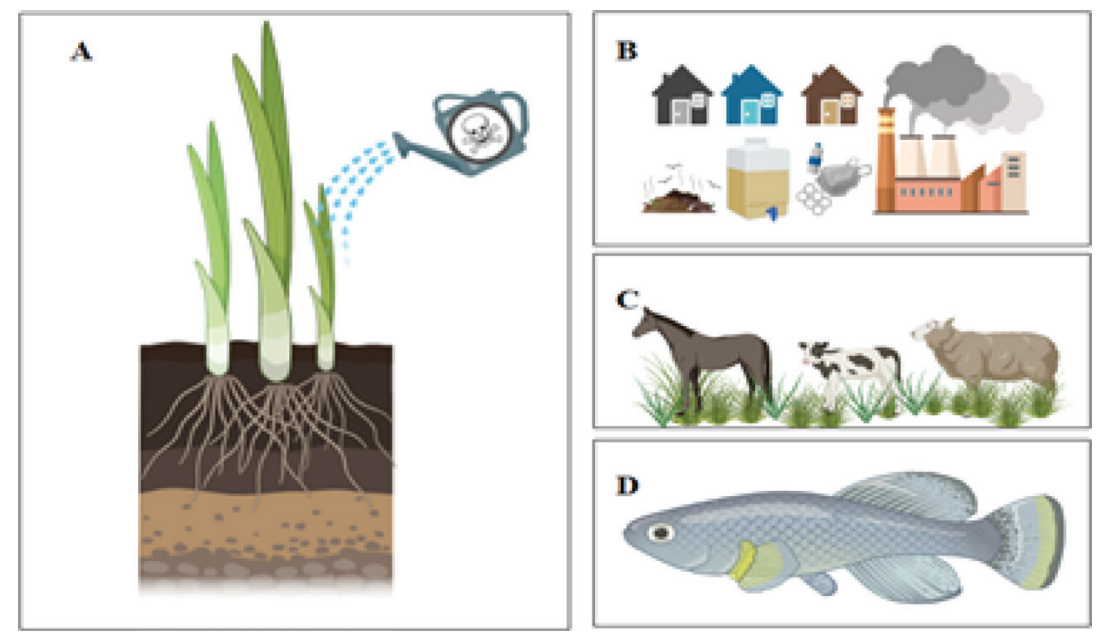

Figura 3. Principales causas de contaminación del Lago de Tota. A) Uso de agentes tóxicos para cultivos agrícolas, especialmente Allium fistulosum. B) Vertimiento de aguas residuales de origen doméstico e industrial provenientes de los municipios de Tota, Cuítiva y

Aquitania. C) Actividad pecuaria en cercanía al lago. D) Desechos de actividad piscícola.

\subsection{Uso de agentes tóxicos para los cultivos agrícolas}

Esta actividad se desarrolla principalmente en los suelos en donde se encuentran los cultivos de cebolla, donde anualmente se aplican alrededor de 430 toneladas de plaguicidas sin ningún control en la dosificación y en la frecuencia de aplicación [19]. Según el estudio reportado por Pérez y cola- boradores (2016) [20] una práctica común entre los agricultores es mezclar tres o más agroquímicos en una sola aplicación, de tal manera que puede contener al mismo tiempo fungicidas, fertilizantes, bioestimulantes y adyuvantes. Entre los fungicidas más usados se encuentran antracol, ridomil y folicur, catalogados con un nivel de toxicidad IV según la agencia de Protección Ambiental de los Estados Unidos (EPA, por su sigla en inglés). Dentro de los 
insecticidas más comunes está Malation, Furadan y Roundup cuyo ingrediente activo es el glifosfato el cual es empleado como herbicida. De acuerdo con lo anterior, existe un riesgo latente relacionado con que el conjunto de estas sustancias pueda caer por escorrentía al lago y, por tanto, conducir a la mineralización, turbiedad y eutrofización de este [1], así como a la afectación en la salud de las poblaciones expuestas, considerando la asociación de tales agentes con genotoxicidad. De manera preocupante, se reporta que alrededor del $74 \%$ de los agricultores nunca han recibido alguna capacitación sobre uso y prácticas adecuadas de este tipo de sustancias [20], lo que los hace aún más susceptibles al desarrollo de enfermedades por exposición ocupacional a plaguicidas.

Finalmente, resulta importante mencionar que el uso anual mundial de pesticidas fue de 2'700.000 toneladas para el año 2012 con un gasto aproximado de 56 mil millones de dólares [21], sugiriendo un posible aumento de estas cifras en el futuro debido al incremento de la población humana, $y$, por tanto, la seguridad alimentaria.

\subsection{Uso de fertilizantes}

La fertilización de los cultivos de la zona se realiza principalmente con abonos orgánicos como la gallinaza, cuya composición se basa en heces, orina, porción no digerible de alimentos, microorganismos de la biota intestinal, plumas y huevos rotos de las gallinas [22], por lo que la gallinaza contiene grandes cantidades de fósforo, nitrógeno, azufre y muchas veces, residuos de antibióticos. Cuando este fertilizante se aplica en exceso, es posible que las fuentes hídricas cercanas se contaminen por escorrentías superficiales debido a la carga inorgánica $\mathrm{y}$ al aumento de organismos patógenos que contiene, adicionalmente, las aguas subterráneas pueden verse afectadas por nitratos al no ser asimilados por el cultivo. El aire también resulta afectado, pues se emiten olores cuando la gallinaza se humedece y se constituye en un ambiente propicio para que las moscas pongan sus huevos y larvas [23].

\subsection{Vertimiento de aguas residuales}

De acuerdo con el plan de ordenamiento territorial departamental de Boyacá [24], el tratamiento de aguas residuales representa uno de los problemas ambientales más críticos del departamento de Boyacá, pues ocasionan contaminación de aguas superficiales y subterráneas generando modificaciones fisicoquímicas y microbiológicas, afectando entre otros la salud humana. Por otro lado, la Gobernación de Boyacá [25] reportó en el 2012 el inadecuado tratamiento en la planta de aguas residuales provenientes de Aquitania por inconvenientes económicos que impiden la operación y mantenimiento de ésta. Además, en el lago es posible encontrar bacterias coliformes como $E$. Coli [26], sólidos suspendidos, compuestos orgánicos biodegradables y refractarios, así como también sólidos inorgánicos disueltos, los cuales pueden causar enfermedades, eutrofización, y problemas relacionados con toxicidad y carcinogénesis [27].

\subsection{Desechos actividad piscícola}

Esta actividad empezó a desarrollarse alrededor del año 1939 empleando trucha arcoíris, catalogada como una de las 100 especies exóticas invasoras más dañinas del mundo. Su introducción al lago de Tota generó daños a especies nativas, además de representar un efecto negativo en la calidad del agua. Expertos afirman que el método actual de cultivo no es viable, pues conduce a un deterioro de la calidad de agua para uso y consumo, pues los restos de alimento junto con las heces producidas por esta especie generan acumulación de Fósforo y concentraciones de amonio, así mismo, con el fin de combatir enfermedades, se producen grandes cantidades de químicos y antibióticos generando el desarrollo de bacterias resistentes [28].

\subsection{Actividad pecuaria}

El deterioro y transformación del paisaje debido a este tipo de prácticas es muy frecuente, el sobrepastoreo conduce a la erosión de suelos $\mathrm{y}$ agotamiento de nutrientes, se drenan los humedales y se contaminan cursos de agua [29]. Además, las heces fecales de los animales generan un aumento en la producción de $\mathrm{CO}_{2}$, metano y amoniaco alterando el ciclo del agua.

\section{ESTUDIOS DE TOXICIDAD Y GENOTOXICIDAD EN COLOMBIA ASOCIADOS A CUERPOS DE AGUAS CONTAMINADAS}

A nivel nacional se han llevado a cabo estudios de genotoxicidad para evaluar las condiciones del 
recurso hídrico, debido a la incertidumbre generada principalmente alrededor de la calidad de agua para consumo humano, pues en muchas ocasiones las fuentes que abastecen a los acueductos vienen cargadas con pesticidas, desechos industriales, aguas negras y subproductos de la cloración [30]. Dicha carga contaminante afecta también de manera directa la fauna y flora propias de cada fuente hidrográfica. La acumulación y presencia de pesticidas en matrices ambientales y sus efectos también ha sido abordada en varios estudios, usando principalmente el ensayo cometa (EC) y el ensayo de micronúcleos (MN) (Tabla 1). Estos ensayos (EC, MN) son aplicables a cualquier población de células eucariotas y se perfilan como los marcadores de daño genético predilectos para la evaluación de citotoxicidad en aguas contaminadas a nivel nacional. Lo anterior debido a su alta sensibilidad para detectar bajos niveles de daño al ADN, rapidez en el conteo de las preparaciones, pequeño tamaño de muestra requerido y flexibilidad [31].

Tabla 1. Estudios de toxicidad y genotoxicidad en Colombia relacionados con aguas contaminadas.

\begin{tabular}{|c|c|c|c|c|}
\hline Agente evaluado & $\begin{array}{l}\text { Recurso hídrico } \\
\text { estudiado }\end{array}$ & Ensayo & Resultados obtenidos & Referencias \\
\hline Cloruro de mercurio & $\begin{array}{l}\text { Laboratorio, } \\
\text { bajo condiciones } \\
\text { controladas }\end{array}$ & $\begin{array}{c}\text { Ensayo de } \\
\text { Micronúcleos (MNs) }\end{array}$ & $\begin{array}{l}\text { Efecto dependiente de dosis y } \\
\text { tiempo de exposición; la especie } \\
\text { nativa (bocachico) fue más sensi- } \\
\text { ble que la foránea (tilapia) a este } \\
\text { agente genotóxico. }\end{array}$ & {$[32]$} \\
\hline $\begin{array}{l}\text { Cadmio, plomo, cobre, } \\
\text { hierro, zinc, magnesio, } \\
\text { manganeso y cromo }\end{array}$ & $\begin{array}{c}\text { Cuenca alta del río } \\
\text { Bogotá }\end{array}$ & $\begin{array}{l}\text { Espectrofotometría } \\
\text { de absorción atómica, } \\
\text { histología de piel, } \\
\text { músculo y branquias }\end{array}$ & $\begin{array}{l}\text { El agua presentó niveles nocivos } \\
\text { de cromo, manganeso, plomo y } \\
\text { hierro, relacionados con las con- } \\
\text { centraciones de estos metales } \\
\text { encontradas en la musculatura y } \\
\text { branquias del capitán de la sabana, } \\
\text { dichas concentraciones superaron } \\
\text { los límites permitidos por la EPA. }\end{array}$ & {$[33]$} \\
\hline $\begin{array}{l}\text { Plaguicidas } \\
\text { organoclorados }\end{array}$ & $\begin{array}{l}\text { Ciénaga grande del } \\
\text { valle bajo del río } \\
\text { Sinú. }\end{array}$ & $\begin{array}{l}\text { Cromatografía de } \\
\text { gases }\end{array}$ & $\begin{array}{l}\text { Pesticidas detectados en muestras } \\
\text { de agua: } \alpha \text {-BCH, } \beta \text {-BCH, } \gamma \text {-BCH, } \\
\text { aldrín y heptacloro epóxido. todos } \\
\text { los pesticidas detectados en todas } \\
\text { las estaciones de muestreo se en- } \\
\text { cuentran sobre el límite permitido } \\
\text { por la ley colombiana }\end{array}$ & {$[34]$} \\
\hline $\begin{array}{l}\text { Extracto orgánico de } \\
\text { agua de mar }\end{array}$ & $\begin{array}{l}\text { Aguas marinas de } \\
\text { orilla y mar adentro } \\
\text { de Coveñas, Sucre }\end{array}$ & $\begin{array}{l}\text { Ensayo cometa sobre } \\
\text { linfocitos humanos }\end{array}$ & $\begin{array}{l}\text { Se observó genotoxicidad a } 37^{\circ} \mathrm{C} \text {, } \\
\text { pero no a } 4{ }^{\circ} \mathrm{C} \text {, este efecto es de- } \\
\text { pendiente de la concentración del } \\
\text { extracto, del sitio de muestreo y de } \\
\text { la interacción de estos dos factores. } \\
\text { La muestra orgánica con menor ge- } \\
\text { notoxicidad fue la de mar adentro. }\end{array}$ & {$[35]$} \\
\hline $\begin{array}{l}\text { Plaguicidas extracto } \\
\text { orgánico }\end{array}$ & $\begin{array}{l}\text { Muestras de aguas } \\
\text { con y sin tratamiento } \\
\text { de la Universidad de } \\
\text { Antioquia }\end{array}$ & Ensayo cometa & $\begin{array}{l}\text { La muestra de agua de la quebrada } \\
\text { el Hato presentó el mayor efecto } \\
\text { genotóxico, la muestra de agua de } \\
\text { la planta de tratamiento presentó } \\
\text { una alta genotoxicidad relativa. }\end{array}$ & {$[36]$} \\
\hline $\begin{array}{l}\text { Plaguicidas } \\
\text { organoclorados }\end{array}$ & $\begin{array}{c}\text { Ciénaga Grande del } \\
\text { Bajo Sinú. }\end{array}$ & $\begin{array}{l}\text { Cromatografía de } \\
\text { gases sobre tejido } \\
\text { muscular }\end{array}$ & $\begin{array}{l}\text { En las especies evaluadas se detec- } \\
\text { taron } \alpha \text {-clordano, endrín y aldrín. } \\
\text { Las concentraciones encontradas } \\
\text { en las especies ícticas de estudio } \\
\text { no representaron toxicidad letal } \\
\text { inmediata. }\end{array}$ & {$[37]$} \\
\hline
\end{tabular}


Diego F. Jaramillo-García - Natalia Rodríguez-Sosa - Marleny Salazar-Salazar

Carlos A. Hurtado-Montaño - Milena Rondón-Lagos

\begin{tabular}{|c|c|c|c|c|}
\hline $\begin{array}{l}\text { Mercurio, zinc, cobre, } \\
\text { plomo y cadmio }\end{array}$ & $\begin{array}{l}\text { Cuenca del río San } \\
\text { Jorge }\end{array}$ & $\begin{array}{c}\text { Ensayo de } \\
\text { Micronúcleos (MNs), } \\
\text { espectrometría de } \\
\text { absorción atómica }\end{array}$ & $\begin{array}{l}\text { Las concentraciones medias de } \mathrm{Hg} \\
\text { en sangre de habitantes de Bocas } \\
\text { de Uré, Puerto Córdoba y mina el } \\
\text { Alacrán excedieron el límite per- } \\
\text { misible }(<5.8 \mu \mathrm{g} / \mathrm{L} \text {; EPA). Daño en } \\
\text { el ADN en sangre de habitantes de } \\
\text { la mina. }\end{array}$ & {$[38]$} \\
\hline $\begin{array}{l}\text { Plaguicidas } \\
\text { organofosforados, } \\
\text { organoclorados, } \\
\text { carbamatos, } \\
\text { ditiocarbamatos }\end{array}$ & $\begin{array}{l}\text { Ribera del río } \\
\text { Bogotá (Suesca) }\end{array}$ & $\begin{array}{l}\text { Cromatografía de } \\
\text { gases, test Michel } \\
\text { (plaguicidas) }\end{array}$ & $\begin{array}{l}\text { Presencia de plaguicidas orga- } \\
\text { noclorados/ organofosforados en } \\
\text { el río y en el tejido de los peces. } \\
\text { Organoclorados y etilentiourea en } \\
\text { muestras biológicas humanas. }\end{array}$ & {$[39]$} \\
\hline Metales pesados & $\begin{array}{l}\text { Aguas del río Cauca } \\
\text { en Cali }\end{array}$ & $\begin{array}{l}\text { Espectrofotometría } \\
\text { de absorción atómica, } \\
\text { test Ames para } \\
\text { mutagenicidad }\end{array}$ & $\begin{array}{l}\text { Índices de mutagenicidad positivos } \\
\text { (IM }>2,0) \text { para muestras colectadas } \\
\text { en temporada lluviosa en tres de } \\
\text { los cinco puntos evaluados. Estos } \\
\text { sitios presentaron a su vez las ma- } \\
\text { yores concentraciones totales de } \\
\text { metales pesados en sus extractos. }\end{array}$ & {$[40]$} \\
\hline Plomo, cadmio, níquel & $\begin{array}{c}\text { Cuenca del río } \\
\text { Magdalena en el } \\
\text { departamento de } \\
\text { Tolima }\end{array}$ & $\begin{array}{c}\text { Ensayo de } \\
\text { Micronúcleos, } \\
\text { Ensayo cometa }\end{array}$ & $\begin{array}{l}\text { Genotoxicidad representada por } \\
\text { la presencia de eritrocitos micro- } \\
\text { nucleados y la formación de los } \\
\text { cometas. Efectos negativos sobre } \\
\text { los recursos ícticos, atribuidos a } \\
\text { una alta descarga de contaminantes } \\
\text { considerados potenciales agentes } \\
\text { mutagénicos. }\end{array}$ & {$[31]$} \\
\hline $\begin{array}{l}\text { Pesticidas, productos de } \\
\text { cloración }\end{array}$ & $\begin{array}{l}\text { Planta potabilizadora } \\
\text { de agua, Pamplona, } \\
\text { Santander }\end{array}$ & Ensayo cometa & $\begin{array}{l}\text { Incremento significativo de la ge- } \\
\text { notoxicidad en los tres sitios ana- } \\
\text { lizados, lo que evidenció la pre- } \\
\text { sencia de compuestos genotóxicos } \\
\text { que constituyen un riesgo para la } \\
\text { población expuesta o consumidora } \\
\text { de estas aguas. }\end{array}$ & {$[30]$} \\
\hline $\begin{array}{c}\text { Cromo, plomo, } \\
\text { sulfuros, cromatos de } \\
\text { zinc y calcio en aguas } \\
\text { residuales }\end{array}$ & $\begin{array}{l}\text { Aguas residuales } \\
\text { de la curtiembre } \\
\text { Tasajero, Cúcuta }\end{array}$ & $\begin{array}{c}\text { Ensayo cometa, test } \\
\text { Ames }\end{array}$ & $\begin{array}{l}\text { Las aguas de desecho de la cur- } \\
\text { tiembre indujeron daño al ADN } \\
\text { en linfocitos humanos. Estas aguas } \\
\text { también aumentaron la tasa de mu- } \\
\text { tagenicidad en la cepa TA98 de } \\
\text { Salmonella typhimurium. }\end{array}$ & {$[41]$} \\
\hline $\begin{array}{l}\text { Cromo, plomo, cadmio, } \\
\text { hierro, zinc y cobre }\end{array}$ & $\begin{array}{l}\text { Aguas residuales de } \\
\text { la curtiembre San } \\
\text { Faustino, Cúcuta }\end{array}$ & $\begin{array}{c}\text { Espectroscopía de } \\
\text { absorción atómica, } \\
\text { test Ames, ensayo } \\
\text { cometa }\end{array}$ & $\begin{array}{l}\text { Las aguas de desecho de la cur- } \\
\text { tiembre indujeron incremento en la } \\
\text { mutagenicidad en las cepas TA98 } \\
\text { y TA100 de Salmonella typhimu- } \\
\text { rium; así como daño al ADN en } \\
\text { linfocitos humanos. }\end{array}$ & {$[42]$} \\
\hline
\end{tabular}

\section{TOXICIDAD EN EL LAGO DE TOTA}

La agricultura, puntualmente el monocultivo de cebolla es sin duda la actividad que mayor grado de transformación genera sobre este ecosistema, ya que como se indicó anteriormente, son múltiples los efectos que se presentan como consecuencia del uso y manejo inadecuado de material orgánico, de productos químicos de uso agrícola (plaguicidas) y de las aguas de riego y escorrentía utilizados para esta labor productiva. Estos tres elementos, sumados a la densidad e intensidad de cultivo son la base de las tensiones ambientales en la cuenca [43]. Dichos efectos han sido evaluados principalmente mediante caracterizaciones fisicoquímicas de agua y sedimentos, estudios de toxicidad en algunos vertebrados e invertebrados presentes en el cuerpo de agua, y la caracterización de los plaguicidas usados en la cuenca. Sin embargo, los estudios de genotoxicidad realizados en el lago son escasos o nulos, por lo que, a la fecha, la frecuencia y tipo de daño celular 
y genético generado por la exposición a las aguas contaminadas del lago de Tota son desconocidos.

Dentro de los estudios realizados para evaluar los efectos de plaguicidas en esta cuenca, se encuentra el estudio publicado recientemente por Barrera y colaboradores (2019) [44], quienes mediante la aplicación de ensayos de toxicidad aguda en Daphnia magna e Hydra attenuata, evidenciaron letalidad negativa o no mayor al $6 \%$ en estas especies. Sin embargo, a pesar de observar baja toxicidad en la cuenca, fue identificada gran cantidad de plaguicidas en los sedimentos incluyendo dicloro difenil tricloroetano (DDT), aldrín, dieldrín, ditiocarbamatos (maneb, mancozeb, metiram, propineb, thiram y ziram) y clorotalonilo. Considerando la ausencia de toxicidad determinada por el estudio, los autores sugieren explorar las afectaciones a largo plazo en comunidades hidrobiológicas nativas e iniciar ensayos de toxicidad crónica con cladóceros, monitoreo in situ con microalgas, pruebas de bioacumulación y/o biomarcadores con $O$. mykiss (trucha arcoíris), macroinvertebrados y perifiton.

Estudios adicionales encontraron trazas de los plaguicidas clorotalonilo, myclobutanil y profenofos, pero no de malatión en muestras de cebolla junca cultivada en la vereda Quebradas, municipio de Aquitania [45]. De acuerdo con los autores, la ausencia de malatión en las muestras de cebolla pudo deberse a diversos factores como alta volatilización o baja persistencia del producto en plantas y suelo, así como a la rápida metabolización de este en la fauna en general. A pesar de no encontrar malatión en los análisis químicos de las muestras, efectos característicos por este producto en la salud de los agricultores encuestados fueron observados, como intoxicaciones, alteraciones dérmicas o cefaleas. El malatión es aplicado en los cultivos de cebolla en la cuenca del lago con alta frecuencia [46]. Lo anterior podría indicar que este plaguicida causa efectos negativos a largo plazo por exposición a bajas concentraciones, en una dosis simple y/o múltiple y en forma repetida en el tiempo [45].

De resaltar que Mojica y Guerrero (2013) [47], a pesar de la existencia de un plan de ordenamiento territorial con abundante información de la región referente a la calidad fisicoquímica y microbiológica de las principales corrientes de agua, evidenciaron escasa información disponible sobre la evaluación de residuos de plaguicidas en matrices ambientales para esta cuenca. En este estudio la presencia de los plaguicidas malatión, difenoconazol, tebuconazol y clorotalonilo, fue identificada en concentraciones por debajo del límite de cuantificación en aguas superficiales de la cuenca del lago de Tota. Movilidad del tebuconazol y difenoconazol por escorrentía hacia el lago de Tota, así como la presencia en sedimentos de malatión y clorotalonilo fueron también identificados en otros estudios [48].

Estudios recientes realizaron la caracterización de los agroquímicos y prácticas agrícolas de uso frecuente entre agricultores con parcelas de escorrentía hacia el lago, encontrando el uso de 183 agroquímicos principalmente para el cultivo de cebolla larga, que comprenden 77 fungicidas, 21 insecticidas, 10 herbicidas, 56 fertilizantes foliares, 5 fertilizantes químicos, 5 hormonas y 9 adyuvantes, además del uso frecuente de cócteles de agroquímicos [20]. Estos hallazgos evidencian la existencia de un alto riesgo de contaminación del suelo y el agua en el área de influencia de la cuenca, factores que simultáneamente pueden aumentar el riesgo para la salud de los agricultores y consumidores de agua y cebolla verde producida en la región. Por lo anterior se hace necesaria la realización de un monitoreo continuo de la calidad del agua y de los posibles contaminantes como herramienta para evaluar el impacto real de cada uno de los riesgos potenciales identificados.

Hallazgos similares fueron reportados por L. Rojas y colaboradores (2015) [49], quienes evidenciaron el uso intensivo de pesticidas como propineb, profenofos, deltametrina y carbofurano en la cuenca del lago de Tota, así como la alta solubilidad y movilidad de oxadixyl (fungicida empleado con frecuencia en actividades agrícolas alrededor del cuerpo de agua) en suelos de cultivo de cebolla. La solubilidad y movilidad de este fungicida podrían conducir a la contaminación de aguas subterráneas y del agua utilizada para consumo humano en la región [50].

De resaltar que el principio activo de los plaguicidas caracterizados e identificados con mayor frecuencia en los diferentes componentes ecológicos y biológicos de la cuenca del lago de Tota son numerosos y variados (Tabla 2). Aldrín y dieldrín no tienen información disponible del nivel de toxicidad debido a que son insecticidas que están descontinuados y son de uso prohibido por parte de la EPA, lo que da un indicio del estado de la regulación del uso de plaguicidas en Colombia y Boyacá, así como de la persistencia de estos compuestos en el ambiente. 
Diego F. Jaramillo-García - Natalia Rodríguez-Sosa - Marleny Salazar-Salazar

Carlos A. Hurtado-Montaño - Milena Rondón-Lagos

Tabla 2. Plaguicidas identificados en diferentes estudios sobre la cuenca del Lago de Tota.

Niveles de toxicidad según la agencia de protección ambiental (EPA): I, altamente tóxico; II, moderadamente tóxico; III, ligeramente tóxico y IV sin riesgo de toxicidad aguda [51].

\begin{tabular}{|c|c|c|c|c|}
\hline Principio activo & Grupo o tipo & Uso - función & Nivel de toxicidad (EPA) & Referencias \\
\hline DDT y congéneres & Organoclorados & Insecticida & III & \multirow{4}{*}{ [44] } \\
\hline Aldrín & Organoclorado & Insecticida & No disponible & \\
\hline Dieldrín & Organoclorado & Insecticida & No disponible & \\
\hline Ditiocarbamatos & Ditiocarbamatos & Fungicida & I a IV & \\
\hline Clorotalonilo & Benzonitrilo, clorado & Fungicida & III & \multirow{3}{*}[45]{} \\
\hline Myclobutanil & Triazol & Fungicida & No disponible & \\
\hline Profenofos & Organofosforado, Clorado & Insecticida & II & \\
\hline Malatión & Organofosforado & Insecticida & III & \multirow{3}{*}[47]{} \\
\hline Difenoconazol & Conazol, clorado & Fungicida & II & \\
\hline Tebuconazol & Azol, clorado & Fungicida & IV & \\
\hline Propineb & Ditiocarbamato & Fungicida & IV & \multirow{4}{*}[20]{} \\
\hline Mancozeb & Ditiocarbamato & Fungicida & III & \\
\hline Dimetomorf & Morfolina, organoclorado & Fungicida & III & \\
\hline Glifosato & Organofosforado & Herbicida & III & \\
\hline Deltametrina & Organofosforado, clorado & Insecticida & II & \multirow{2}{*}{ [49] } \\
\hline Carbofurano & Carbamato & Insecticida & I & \\
\hline Oxadixyl & Anilida, oxazalidina & Fungicida & III & {$[50]$} \\
\hline
\end{tabular}

\section{PEZ CEBRA (Danio rerio)}

\subsection{Características generales}

El pez cebra es originario del sur asiático y presenta una amplia distribución. Se trata de un teleósteo actinopterigio (Actinopterygii) perteneciente a la familia cyprinidae que proviene del linaje de peces con aletas radiadas, uno de los dos grupos principales de vertebrados óseos [52] pues comprende más de 3600 especies.

La organización del cuerpo del pez cebra es similar al morfotipo general osteíctio y la disposición general del sistema nervioso o de los órganos de los sentidos es aquel compartido por la mayoría de los gnatóstomos [53]. Este individuo se caracteriza por presentar un tamaño reducido, una tonalidad particular representada por tres tipos de células: melanóforos, xantófitos e iridóforos, además de contar con una línea lateral incompleta que llega hasta la base de la aleta pélvica. Estos peces cuentan con dimorfismo sexual pues los machos tienden a ser más pequeños que las hembras, con aletas anales más grandes, mientras que, las hembras presentan vientre convexo y abultado [54].

\subsection{Pez cebra como modelo biológico}

El pez cebra es un organismo importante como modelo para el estudio de los vertebrados en una gran variedad de disciplinas biológicas, debido a que presenta una serie de ventajas como el desarrollo externo y la transparencia del embrión que permiten estudios de su desarrollo temprano. Adicionalmente, su alta fecundidad y rápida generación facilitan los análisis genéticos y pueden ser fácilmente mantenidos en acuarios. Por ello, 
el pez cebra ha adquirido gran importancia en los últimos años, ya que ha resultado ser un excelente modelo en el estudio de diversas patologías y enfermedades humanas, entre las que se encuentra el cáncer [55, 56], en química toxicológica, en estudios de neurobiología (neuroanatómicos y neuroquímicos) [53] y en la evaluación de los efectos de las exposiciones ambientales a diversos compuestos [57].

El pez cebra y el ser humano comparten gran parte del genoma (aproximadamente el $70 \%$ ) incluyendo $82 \%$ de genes asociados a enfermedades como el cáncer, Alzheimer, Parkinson y cardiopatías [58] (Figura 4A). A este respecto, se han realizado descripciones detalladas de la anatomía del embrión y la larva del pez cebra, y se han desarrollado metodologías robustas que permiten la experimentación. Dentro de tales metodologías, la mutagénesis a gran escala ha sido estudiada en este modelo biológico para indagar acerca de las alteraciones cromosómicas numéricas (aneuploidía) y estructurales, la función de genes y la heterogeneidad característica de enfermedades como el cáncer (Figura 4B).

Este organismo, además de poseer genes similares a los humanos, también se destaca por compartir un alto nivel de homología fisiológica, en donde se incluye el cerebro, el tracto digestivo, la musculatura y el sistema inmune innato (Figura $4 \mathrm{C}$ ), por lo que se calcula de forma aproximada que se pueden reproducir en pez cebra ocho de cada diez enfermedades humanas [59], incluyendo la inducción de tumores en una amplia variedad de órganos como el hígado, el páncreas, el canal intestinal, la piel, los músculos, la vasculatura y los testículos [60]. Adicionalmente es posible inducir diferentes mutaciones genéticas o activar vías de señalización mediante el uso de productos químicos.
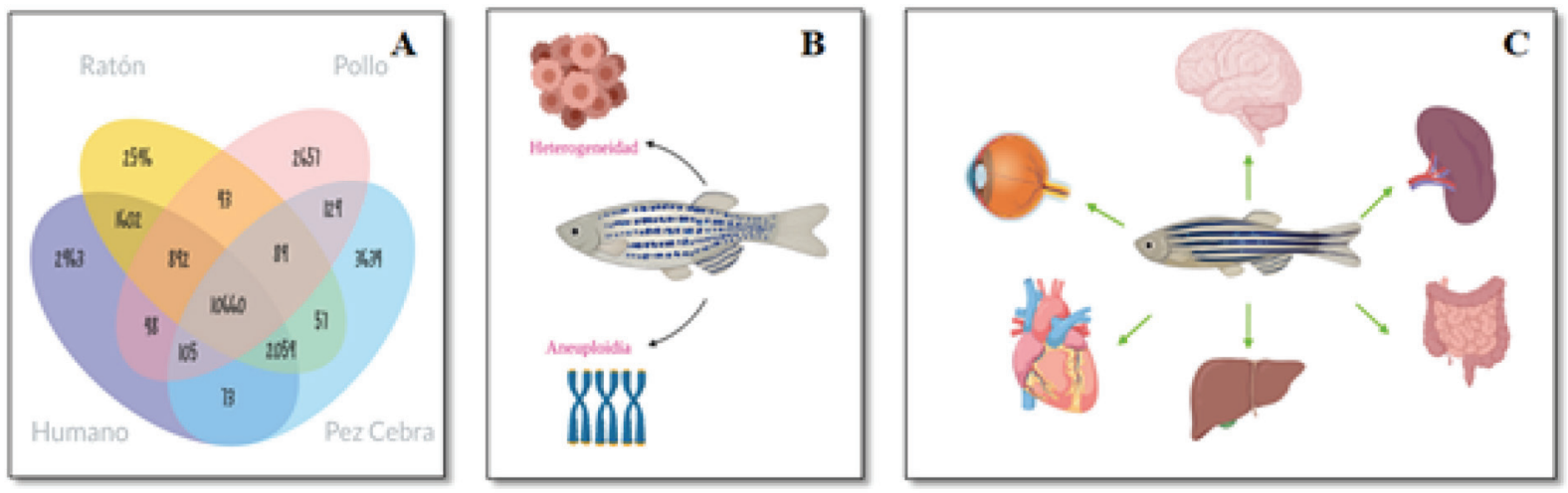

Figura 4. Características del pez cebra como modelo biológico. El pez cebra se constituye como un excelente modelo biológico para estudios de toxicidad y genotoxicidad considerando que A) Comparte con el ser humano aproximadamente el 70\% del genoma. B) Capacidad de imitar el carcinoma humano, ya que exhibe aneuploidía masiva y heterogeneidad en el mismo tumor. C) Comparte un alto nivel de homología fisiológica, en donde se incluye el cerebro, el tracto digestivo, la musculatura, y el sistema inmune innato.

La incorporación del pez cebra al listado de animales empleados en los procedimientos experimentales ha supuesto la consolidación de este modelo animal. Su uso se ha incrementado debido a sus ventajosas características, permitiendo enfocar numerosas áreas de estudio desde nuevas perspectivas [61]. En diversos estudios de toxicidad se ha determinado la capacidad que presenta el pez cebra en su regeneración, adaptación y respuesta inmune ante altas concentraciones de químicos como arsénico, plomo y glifosato [62].

Por último, resulta importante destacar la importancia del uso del pez cebra en las formas embrionarias como una alternativa para estudios toxicológicos, microbiológicos, etnobotánicos y neurológicos, entre otros. Lo anterior debido a la reducción de costos y de residuos, reducción de dolor y angustia en los animales, así como la factibilidad al predecir efectos a corto plazo en cada estudio [63]. Adicionalmente, su estudio representa un gran valor para la salud y prevención, pues la exposición humana a químicos ambientales se encuentra asociada a toxicidad aguda y consecuencias a largo plazo, que incluyen anormalidades congénitas, crónicas, cáncer e incluso, muerte [57]. 
Diego F. Jaramillo-García - Natalia Rodríguez-Sosa - Marleny Salazar-Salazar

Carlos A. Hurtado-Montaño - Milena Rondón-Lagos

\subsection{Pez cebra en estudios de Toxicidad y Genotoxicidad}

Durante décadas el pez cebra se ha empleado para pruebas de toxicidad ambiental y calidad del agua, siendo la primera especie de pez en la cual se desarrollaron experimentos asociados a carcinogénesis. Embriones de pez cebra expuestos a carcinógenos exhiben una amplia variedad de neoplasias que se derivan principalmente de tejidos epiteliales, mesenquimáticos y neurales, donde el hígado representa el principal órgano afectado por exposición a este tipo de agentes en cualquier etapa de desarrollo [64].

Muchos de estos agentes tóxicos se introducen en el medio ambiente, especialmente por medio del vertimiento de aguas residuales en fuentes hídricas y a medida que pasan los años, la presencia de estos agentes tiende a ser mayor. De acuerdo con lo anterior, la contaminación de ecosistemas acuáticos y su efecto en las poblaciones que allí se alojan, han sido reconocidas como una de las principales emergencias ambientales actuales [65].

Considerando lo anterior, el pez cebra se constituye en un excelente modelo biológico y en un prototipo ideal para la evaluación de los efectos genotóxicos por exposición ocupacional o ambiental a sustancias químicas [65], debido a su sensibilidad a los contaminantes, sensibilidad evidenciada por el daño al material genético (rupturas, mutaciones como inserciones y deleciones). A lo anterior se suma que en la actualidad existen pocos modelos animales en los cuales sea posible conocer los efectos de la exposición a sustancias tóxicas [57]. De hecho, son varios los estudios que muestran la utilidad del pez cebra en estudios biológicos. Por ejemplo, M. Tye y colaboradores (2019) [66], demostraron que las toxinas en solución pueden transportarse fácilmente en peces a través de las membranas permeables como epitelios branquiales, mucosas nasales y orales, observando mejores resultados en los embriones de pez cebra, debido a que estos absorben de manera más sencilla dichas toxinas por la permeabilidad que posee tanto su corion como sus membranas vitelinas. Adicionalmente, los compuestos nocivos también pueden ingresar al pez mediante el consumo de alimentos que se encuentran contaminados con agentes tóxicos los cuales son absorbidos por su intestino delgado. Más aún, ha sido que el pez cebra exhibe transferencia materna de compuestos tóxicos a los ovocitos los cuales conducen a una alteración en la expresión génica [66], lo que lo hace aún más atractivo para estudios de genotoxicidad.

Por ejemplo, la utilidad de pez cebra en la evaluación de la citotoxicidad y genotoxicidad del insecticida carbaryl ha sido recientemente demostrada por M. Pandey y colaboradores (2015) [67]. En este estudio se demostró que la exposición a este insecticida induce citotoxicidad moderada en las células de las branquias del pez cebra, así como alteraciones en el desarrollo temprano del embrión [67]. Efectos genotóxicos fueron también reportados en el pez cebra por exposición al Cadmio, siendo observadas altas concentraciones de este metal en las branquias, el hígado, el músculo esquelético y en el cerebro después de 21 días de exposición [68]. Los anteriores hallazgos son muy importantes teniendo en cuenta que este es uno de los metales pesados presentes en el lago de Tota [25]. Este metal presenta un efecto negativo a nivel celular ya que además de activar algunos protooncogenes e inhibir el sistema de reparación del material genético, también inhibe enzimas involucradas en la respuesta al estrés oxidativo [68].

De la misma manera, el pez cebra ha sido usado ampliamente como modelo para evaluar el daño genético y cromosómico generado por exposición a plaguicidas (Tabla 3 ).

Tabla 3. Estudios a nivel internacional de toxicidad y genotoxicidad en pez cebra.

\begin{tabular}{|c|c|c|c|c|}
\hline Agente evaluado & $\begin{array}{l}\text { Lugar de } \\
\text { estudio }\end{array}$ & Ensayo usado & Resultados observados & Referencias \\
\hline $\begin{array}{c}\text { Carbamazepina, } \\
\text { Diclofenaco }\end{array}$ & $\begin{array}{l}\text { Río Volturno. } \\
\text { Italia }\end{array}$ & $\begin{array}{l}\text { 1. Ensayo cometa. } \\
\text { Ensayo de difusión } \\
\text { RAPD-PCR }\end{array}$ & $\begin{array}{l}\text { 2. Pérdida significativa de la integridad } \\
\text { del ADN. }\end{array}$ & {$[65]$} \\
\hline
\end{tabular}




\begin{tabular}{|c|c|c|c|c|}
\hline Carbarilo & $\begin{array}{l}\text { Laboratorio, } \\
\text { condiciones } \\
\text { controladas, } \\
\text { China }\end{array}$ & $\begin{array}{l}\text { 1. Absorción de rojo } \\
\text { neutro (NRU). } \\
\text { 2. Ensayo cometa. } \\
\text { 3. Liberación de lactato } \\
\text { deshidrogenasa (LDH) }\end{array}$ & $\begin{array}{l}\text { Citotoxicidad moderada y muerte de } \\
\text { células branquiales por necrosis. }\end{array}$ & {$[67]$} \\
\hline Cadmio & $\begin{array}{l}\text { Laboratorio, } \\
\text { condiciones } \\
\text { controladas, } \\
\text { Francia }\end{array}$ & RAPD-PCR & $\begin{array}{l}\text { Tasas elevadas de mortalidad en pez } \\
\text { cebra que alcanzaron } 28 \% \text { y } 56 \% \text { de } \\
\text { pérdida de peces en las concentracio- } \\
\text { nes usadas. }\end{array}$ & [68] \\
\hline Arsénico & $\begin{array}{l}\text { Pozo UAEH, } \\
\text { P. V Zimapán, } \\
\text { México }\end{array}$ & $\begin{array}{l}\text { Ensayo de Micronúcleos } \\
\text { (MNs) }\end{array}$ & $\begin{array}{l}\text { Mayor inducción de MNs en el control } \\
\text { positivo que en el control negativo. }\end{array}$ & [69] \\
\hline Nitrato de plomo & $\begin{array}{l}\text { Laboratorio, } \\
\text { condiciones } \\
\text { controladas, } \\
\text { Colombia }\end{array}$ & $\begin{array}{l}\text { Pruebas de toxicidad } \\
\text { aguda }\end{array}$ & $\begin{array}{l}\text { La mortalidad no fue superior al } 50 \% \\
\text { en ninguna de las concentraciones uti- } \\
\text { lizadas. }\end{array}$ & {$[70]$} \\
\hline Glifosato & $\begin{array}{l}\text { Laboratorio, } \\
\text { condiciones } \\
\text { controladas, } \\
\text { Brasil }\end{array}$ & $\begin{array}{l}\text { 1. Pruebas de toxicidad } \\
\text { aguda. } \\
\text { 2. Ensayo cometa }\end{array}$ & $\begin{array}{l}\text { Efectos tóxicos en el pez cebra en eta- } \\
\text { pas tempranas de la vida. }\end{array}$ & {$[71]$} \\
\hline $\begin{array}{l}\text { Clorpirifos, } \\
\text { diclorvos, diazinón }\end{array}$ & $\begin{array}{l}\text { Laboratorio, } \\
\text { condiciones } \\
\text { controladas, } \\
\text { Estados Unidos }\end{array}$ & Pruebas toxicidad aguda & $\begin{array}{l}\text { Disminución de supervivencia de los } \\
\text { organismos evaluados, así como dis- } \\
\text { minución en la frecuencia cardíaca y } \\
\text { la actividad larval. }\end{array}$ & {$[72]$} \\
\hline Aguas residuales & $\begin{array}{l}\text { Río Jialu, en } \\
\text { China }\end{array}$ & $\begin{array}{l}\text { 1. Pruebas de toxicidad } \\
\text { aguda. } \\
\text { 2. ELISA. } \\
\text { 3. Citometría de flujo }\end{array}$ & $\begin{array}{l}\text { Aguas residuales municipales cau- } \\
\text { saron citotoxicidad y daño oxidativo } \\
\text { significativo en el ADN del pez cebra }\end{array}$ & {$[73]$} \\
\hline Sedimentos & $\begin{array}{l}\text { Río Yangtze, } \\
\text { China }\end{array}$ & Ensayo cometa & $\begin{array}{l}\text { Anormalidades en etapas del desarro- } \\
\text { llo, reducción en la tasa de eclosión y } \\
\text { en la frecuencia cardíaca de los em- } \\
\text { briones de pez cebra. Genotoxicidad } \\
\text { significativa en las muestras en rela- } \\
\text { ción con los controles. }\end{array}$ & {$[74]$} \\
\hline Monocrotofos & $\begin{array}{l}\text { Laboratorio, } \\
\text { condiciones } \\
\text { controladas, } \\
\text { India }\end{array}$ & $\begin{array}{l}\text { 1. Ensayo cometa. } \\
\text { 2. Ensayo Micronúcleos } \\
\text { (MNs) }\end{array}$ & $\begin{array}{l}\text { Daño significativo en ADN de todos } \\
\text { los peces tratados con plaguicidas en } \\
\text { comparación con el control. Aumen- } \\
\text { to en el porcentaje de cola de ADN } \\
\text { y en la frecuencia de MNs a medida } \\
\text { que aumentaba la concentración del } \\
\text { compuesto. }\end{array}$ & {$[75]$} \\
\hline $\begin{array}{l}\text { Carbendazim, } \\
\text { dinitrotolueno, indol }\end{array}$ & $\begin{array}{l}\text { Laboratorio, } \\
\text { condiciones } \\
\text { controladas, } \\
\text { Alemania }\end{array}$ & Pruebas toxicidad aguda & Máxima toxicidad & {$[76]$} \\
\hline Aguas residuales & $\begin{array}{l}\text { Río Ocoa, } \\
\text { Colombia }\end{array}$ & $\begin{array}{l}\text { 1. Ensayo de } \\
\text { Micronúcleos (MNs) } \\
\text { 2. Histopatología }\end{array}$ & $\begin{array}{l}\text { Disminución en el recuento de eritroci- } \\
\text { tos, linfocitos, así como en la concen- } \\
\text { tración de hemoglobina y porcentaje } \\
\text { de hematocritos. Aumento de los re- } \\
\text { cuentos de trombocitos y neutrófilos. } \\
\text { Aumento de la frecuencia de MNs en } \\
\text { las especies ícticas evaluadas. }\end{array}$ & {$[77]$} \\
\hline
\end{tabular}


Diego F. Jaramillo-García - Natalia Rodríguez-Sosa - Marleny Salazar-Salazar

Carlos A. Hurtado-Montaño - Milena Rondón-Lagos

\begin{tabular}{cclll}
\hline $\begin{array}{c}\text { Magnesio, sodio, } \\
\text { cloruros, sulfatos, } \\
\begin{array}{c}\text { E. coli } \\
\text { Bangalore, India }\end{array}\end{array}$ & $\begin{array}{c}\text { Lago Ibalur, } \\
\text { Banálisis fisicoquímicos }\end{array}$ & $\begin{array}{l}\text { Efectos nocivos sobre el pez cebra } \\
\text { debido a las aguas contaminadas del } \\
\text { lago. }\end{array}$ & {$[78]$} \\
\hline $\begin{array}{c}\text { Sustancias químicas/ } \\
\text { efectos teratogénicos } \\
\text { en agua contaminada }\end{array}$ & $\begin{array}{c}\text { Río Atoyac, } \\
\text { México }\end{array}$ & $\begin{array}{l}\text { Prueba de } \\
\text { embriotoxicidad de peces }\end{array}$ & $\begin{array}{l}\text { Letalidad y teratogenicidad altas. } \\
\text { ca del río por la influencia de la acti- } \\
\text { vidad agrícola. }\end{array}$ & [79] \\
\hline
\end{tabular}

Relacionado con lo anterior, O. Báez y colaboradores (2004) [69], observaron alta frecuencia de micronúcleos (MN) en las células de las branquias del pez cebra cultivada en agua con Arsénico (Figura 5). Estos resultados llevaron a los autores a concluir que la exposición prolongada a Arsénico provoca daños cromosómicos en el pez cebra (Figura 5A). El pez cebra ha sido también usado como modelo para evaluar el efecto de dosis subletales de Nitrato de Plomo $\left(\mathrm{Pb}\left(\mathrm{NO}_{3}\right)_{2}\right)$ [70]. Los resultados de este estudio mostraron que el Nitrato de Plomo es un agente teratogénico que incide altamente en las malformaciones del pez cebra incluyendo cifosis, lordosis, escoliosis, espina bífida, edema pericárdico, hemorragia cefálica, hipertrofia de aletas caudales y vitelo adicional (Figura 5B).

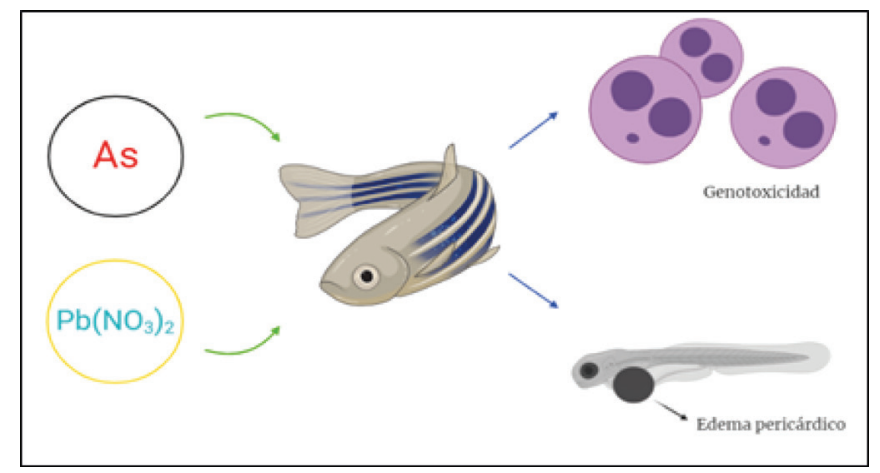

Figura 5. Genotoxicidad y teratogénesis inducida en el pez cebra por exposición a agentes químicos. A) Inducción de micronúcleos (MNs) por exposición a Arsénico (As). B) Embrión con edema pericárdico producto de la exposición a Nitrato de Plomo $\mathrm{Pb}\left(\mathrm{NO}_{3}\right)_{2}$.

Estudios recientes indican que plaguicidas como el glifosato afectan a los embriones del pez cebra y permanecen en cuerpos de agua durante aproximadamente 60 días después de su aplicación [71]. De hecho, debido a que el pez cebra puede bioacumular muchos contaminantes durante una exposición de 21 días, tales exposiciones extensas causan daño al material genético $(\mathrm{ADN})$ y a las células hepáticas [73].

De resaltar que una práctica muy común entre los agricultores del lago de Tota es la mezcla de varios plaguicidas a la vez [20], práctica que resulta alarmante, considerando previos estudios que indican el efecto mutagénico y genotóxico que tales mezclas inducen en el pez cebra [76], por lo que el uso de biomarcadores genéticos, para determinar alteraciones relacionadas con genotoxicidad, resultan de gran importancia en nuestro departamento. Los estudios realizados hasta la fecha demuestran que el pez cebra es un modelo biológico de gran importancia para el desarrollo de estudios de toxicidad y genotoxicidad por exposición a fuentes hídricas contaminadas como lo es el lago de Tota.

\section{CONCLUSIONES}

El lago de Tota comprende una serie de servicios ecosistémicos de gran importancia, los que se han ido deteriorando debido al amplio uso de plaguicidas en los cultivos agrícolas. Estas actividades han contribuido a la contaminación observada en la actualidad, siendo esta una problemática ambiental en constante ascenso, donde la salud, el desarrollo de las comunidades y los procesos ecológicos se han visto afectados. Las investigaciones realizadas hasta la fecha muestran la alta toxicidad presente en el lago de Tota, donde muchas de las 
sustancias químicas allí identificadas han sido catalogadas como precursoras de enfermedades, incluyendo cáncer. Sin embargo, a pesar de la problemática ambiental que representa la contaminación del lago de Tota, son muy pocos los estudios que reportan el daño celular y genético que se podría generar por el consumo y exposición a los agentes tóxicos y químicos presentes en esta cuenca. A este respecto, un modelo para estudios de genotoxicidad y toxicidad que ha adquirido gran importancia en los últimos años dada su alta homología genética con el ser humano lo constituye el pez cebra. Aumentar nuestro conocimiento acerca de los efectos tóxicos y genotóxicos de las aguas del lago de Tota permitirá no sólo adoptar medidas para la protección y seguimiento de las poblaciones expuestas sino el establecimiento de programas educativos para el correcto manejo de plaguicidas y para la protección de esta cuenca.

\section{AGRADECIMIENTOS}

Los autores expresan sus agradecimientos al Semillero de Investigación en Ciencias Básicas y Aplicadas (SICBA), al Grupo de Investigación en Ciencias Biomédicas UPTC (GICBUPTC), a la Universidad Pedagógica y Tecnológica de Colombia y a la Universidad del Quindío.

\section{REFERENCIAS}

[1] República de Colombia - Departamento Nacional de Planeación - CONPES 3801, "Conpes 3801 - Manejo Ambiental Integral de la Cuenca Hidrográfica del Lago de Tota". Bogotá, 2014 [En línea] Disponible: https:// colaboracion.dnp.gov.co/CDT/Conpes/ Económicos/3801.pdf

[2] C. Montañez, "Caracterización y mapeo participativo de servicios ecosistémicos en paisajes socio-ecológicos de producción.”. Pontificia Universidad Javeriana, 2018.

[3] CorpoBoyacá, "Plan de ordenación y manejo de la cuenca del lago de Tota". Boyacá, 2017. [En línea] Disponible: https:// www.corpoboyaca.gov.co/cms/wp-content/ uploads/2015/11/diagnostivo-problematicaambiental-lago-tota.pdf

[4] P. Chaparro et al., "Mortalidad debida a intoxicación por plaguicidas en Colombia entre 1998 y 2011", Rev. Biomédica, vol. 35, no. 1, pp. 2-37, 2015, [En línea]. Disponible: https://www.minsalud.gov.co/sites/ rid/Lists/BibliotecaDigital/RIDE/IA/INS/ mortalidad-debida-intoxicacion-plagucidascolombia-1998-2011.pdf

[5] S. Díaz et al., "Niveles de colinesterasa en cultivadores de papa expuestos ocupacionalmente a plaguicidas, Totoró, Cauca", Rev. Univ. Ind. Santander. Salud, vol. 49, no. 1, pp. 85-92, Mar. 2017, doi: 10.18273/revsal. v49n1-2017008.

[6] IDEAM, "Informe batimetría lago de tota", Bogotá, 2014. [En línea]. Disponible: http:// www.ideam.gov.co/documents/14691/16003/ Batimetria+Lago+de+Tota/6d14dla2-a91b4a20-86e3-58cb4242a616.

[7] A. Y. V. Cardozo et al., "Holocene paleolimnological reconstruction of a high altitude Colombian tropical lake", Rev. Palaeogeogr. Palaeoclimatol. Palaeoecol., vol. 415, pp. 127-136, Dec. 2014, doi: 10.1016/j.palaeo.2014.03.013

[8] A. Espinosa, "El agua, un reto para la salud pública La calidad del agua y las oportunidades para la vigilancia en Salud Ambiental", Universidad Nacional de Colombia, 2018.

[9] WAVES and Corpoboyacá, "Contabilidad Ambiental y Económica para el Agua: Caso Piloto para la Cuenca del Lago de Tota", Boyacá, 2016. [En línea]. Disponible: http:// www.corpoboyaca.gov.co/cms/wp-content/ uploads/2016/05/Informe-cuenta-del-aguaLago-Tota-.pdf.

[10] J. Vela, "Plan de Ordenación y Manejo de la Cuenca del Lago de Tota, CorpoboyacáPontificia Universidad Javeriana" Boyacá, 2005. [En línea]. Disponible: https:// www.corpoboyaca.gov.co/cms/wp-content/ uploads/2015/11/diagnostivo-sistemasproductivos-lago-tota.pdf.

[11] EVA, "Agricultura y desarrollo rural", Gobierno de Colombia, 2018. https://www.datos.gov.co/Agricultura-y-Desarrollo-Rural/ Evaluaciones-Agropecuarias-MunicipalesEVA/2pnw-mmge/data (accessed May 04, 2020).

[12] C. González, "Impactos de la variabilidad climática y actividades humanas en la dinámica 
hidrológica del Lago de Tota", Universidad de Antioquia, 2016.

[13] ICA, “Censo pecuario Nacional”, Gobierno de Colombia, 2017. https://www.ica.gov. co/areas/pecuaria/servicios/epidemiologiaveterinaria/censos-2016/censo-2017.aspx (accessed May 04, 2020).

[14] EVA, "Piscicultura - Alevinaje Boyacá", Gobierno de Colombia, 2018. https://www. datos.gov.co/Agricultura-y-DesarrolloRural/Pisc-cultura-Alevinaje-DEPARTAMENTO-DE-BOYAC-/fqjc-4zb2/data (accessed May 04, 2020).

[15] B. Ávila et al., "Diseño de un sistema tecnificado para el aumento de la productividad piscícola en la finca 'La laguna' en el municipio de San Pablo de Borbur, Boyacá", Universidad de Cundinamarca, 2019.

[16] E. Cristancho et al., "Contaminación de la principal fuente hídrica de Boyacá - Impacto tecnológico agropecuario", Duitama, 2018. [En línea]. Disponible: https://www. researchgate.net/publication/325881152 CONTAMINACION DE LA PRINCIPAL_FUENTE_HIDRICA D DE BOYACA_LAGO_DE TOTA_2015-2018_IMPACTO_TECNOLOGICO_AGROPECUARIO CONTAMINACION DE LA PRINCIPAL_FUENTE_HIDRICA_DE_BOYACA_LĀGO_DE_TOTA_2015-2018_IMPACTO_TEC.

[17] A. González et al., "Filtros verdes: agua limpia para Colombia”, Bogotá, 2016. [En línea]. Disponible: https://media-ashoka. oiengine.com/attachments/fa959aa9-002f4cf0-8c99-8b0dc99a0c08.pdf

[18] N. Aranguren et al., "Sources of nutrients behind recent eutrophication of Lago de Tota, a high mountain Andean lake", Rev. Aquat. Sci., vol. 80, no. 4, pp. 39, Oct. 2018, doi: 10.1007/s00027-018-0588-x.

[19] J. Abella et al., "Contribución de un afluente tributario a la eutrofización del lago de Tota (Boyacá, Colombia", Rev. Col. Qui., vol. 41, no. 2, pp. 243-262, Jul. 2012, [En línea]. Disponible: http://www.scielo.org.co/pdf/ rcq/v41n2/v41n2a6.pdf

[20] W. Pérez et al., "Identification of the main active ingredients of agrochemicals used around the Lake of Tota, Colombia", Rev. Cien. Agri., vol. 13, no. 1, pp. 91-106, Dic. 2016, [En línea]. Disponible: https://revistas. uptc.edu.co/index.php/ciencia_agricultura/ article/view/4809/3875

[21] I. Gonçalves et al., "Toxicity testing of pesticides in zebrafish - a systematic review on chemicals and associated toxicological endpoints", Rev. Env. Sci. Pollut. Res., vol. 27, no. 10, pp. 10185-10204, Feb. 2020, doi: 10.1007/s11356-020-07902-5

[22] L. Carhuancho et al., "Gestión ambiental de residuos avícolas mediante digestión anaerobia para la producción de fertilizantes orgánicos líquidos", Rev. Ancient. Univ. Centro Perú., vol. 76, no. 1, pp. 125-132, Jul. 2014, doi: doi.org/10.21704/ac.v76i1.773

[23] ICA, "Manejo de la gallinaza y su utilización como abono en la agricultura", Gobierno deColombia, 2008. https://repository.agrosavia.co/ bitstream/handle/20.500.12324/34918/66569. pdf? sequence $=1 \&$ isAllowed $=y$ (accessed May 04, 2020).

[24] Gobernación de Boyacá, “Ordenamiento territorial departamental de Boyacá Dimensión funcional: Servicios públicos e infraestructura", Boyacá, 2018. [En línea]. Disponible:https://www.dapboyaca.gov.co/ wp-content/uploads/2018/09/DIMENSIONFUNCIONAL_SERVICIOS_INFRAESTRUCTURA.pdf

[25] Gobernación de Boyacá, "Mapa de riesgo de la calidad del agua para el consumo humano de la Laguna de Tota, fuente abastecedora del casco urbano de los municipios de Firavitoba y Cuítiva", Boyacá, 2012. [En línea]. Disponible: https://www.boyaca.gov. co/secretariasalud/wp-content/uploads/ sites/67/2014/07/images_Documentos_ Salud_Publica_Ano_2014_AGUA_CONSUMO_HUMANO_MAPA_RIESGO_ MAPA-DE-RIESGO-DE-LA-LAGUNADE-TOTA.pdf

[26] J. Valderrama, "Cambios institucionales para preservar la cantidad y la calidad del agua en la cuenca del Lago de Tota", Pontificia Universidad Javeriana, 2013.

[27] J. Lizarazo et al., "Sistemas de plantas de tratamiento de aguas residuales en Colombia," Universidad Nacional de Colombia, 2013. 
[28] N. Torres et al., "Estimación de los desperdicios generados por la producción de trucha arcoíris en el lago de Tota, Colombia", Rev. Corpoica. CienTecnol. Agropecuaria., vol. 18, no. 2, pp. 247-255, En. 2017, doi: doi. org/10.21930/rcta.vol18_num2_art:631

[29] R. Primack et al., "¿Qué es la biología de la conservación?", en Fundamentos de conservación biológica: Perspectivas Latinoamericanas", Rev. F. de C. Económica. 1 ed. México. 2001, pp. 35-58.

[30] I. Meléndez et al., "Actividad genotóxica de aguas antes y después de clorar en la planta de potabilización empopamplona", Rev. Bistua, vol. 13 no. 2, Mar. 2015, [En línea]. Disponible: http://revistas.unipamplona.edu. co/ojs_viceinves/index.php/BISTUA/article/ view/1795/764

[31] L. Ortegón et al., Efectos genotóxicos de los contaminantes ambientales, en peces de importancia comercial del río Magdalena, en el departamento del Tolima. Rev. Tumbaga. vol. 1, no. 9. pp. 21-53. Jul. 2014. [En línea] Disponible: http://revistas.ut.edu.co/index. php/tumbaga/article/view/645/502

[32] M. Peñaloza et al., Genotoxicidad del Cloruro de Mercurio en dos especies ícticas Prochilodus magdalenae y Oreochromis sp. Rev. Actual. Biol. vol. 25 no. 79, pp. 105-111, Jun. 2003. [En línea] Disponible: https://revistas.udea.edu.co/index.php/actbio/article/ view/329490/20785928

[33] A. Rodríguez et al., Bioacumulación por metales metales pesados en el capitán de la sabana (Eremophilus mutisii) habitante de la cuenca alta del río Bogotá. Rev. Electrónica de Ingeniería en Producción Acuicola. vol. 3 no. 3, pp. 101-115, 2007. [En línea] Disponible: https://revistas.udenar.edu.co/index. php/reipa/article/view/1629

[34] E. Lans et al., Estudio de la contaminación por pesticidas organoclorados en aguas de la ciénaga grande del valle bajo del río Sinú. Rev. RTA. vol. 13, no. 1, pp. 49-56. Ene. 2008. [En línea] Disponible: https://revistas. unicordoba.edu.co/index.php/temasagrarios/article/view/664/780

[35] W. Soler et al., Baja genotoxicidad de extracto orgánico de agua de mar de Coveñas (Sucre, Colombia). Rev. Vitae. vol. 15, no.
1, pp. 96-102. Ene. 2008. [En línea] Disponible: http://www.scielo.org.co/pdf/vitae/ v15n1/v15n1a12.pdf

[36] F. Tobón et al., Genotoxicidad del agua contaminada por plaguicidas en un área de Antioquia, Rev. MVZ Córdoba. vol. 16, no. 2, pp. 2605-2615. Ene. 2011. [En línea] Disponible: https://www.researchgate. net/publication/262444014_Genotoxicidad_del_agua_contaminada_por_plaguicidas_en_un_area_de_Antioquia

[37] E. Lans et al., Compuestos organoclorados residuales en dos especies ícticas de la Ciénaga Grande del Bajo Sinú, Córdoba, Colombia. Rev. MVZ Córdoba. vol. 16, no. 1, pp. 2402-2409. Jul. 2011. [En línea] Disponible: http://www.scielo.org.co/pdf/mvz/ v16n1/v16n1a16.pdf

[38] G. Madrid et al., Genotoxicidad de metales pesados $(\mathrm{Hg}, \mathrm{Zn}, \mathrm{Cu}, \mathrm{Pb}$ y $\mathrm{Cd})$ asociado a explotaciones mineras en pobladores de la cuenca del río San Jorge del Departamento de Córdoba, Colombia. Rev. Asoc. Col. Cienc. vol. 23, pp: 103-111. Mar. 2011. [En línea] Disponible: https://quimicos.minambiente.gov.co/images/Mercurio/genotoxicidad_metales_pesados.pdf

[39] A. Salcedo et al., Exposición a plaguicidas en los habitantes de la ribera del río Bogotá (Suesca) y en el pez Capitán. Rev. Cienc. Salud. vol. 10, pp: 29-41. Sep. 2012. [En línea] Disponible: https://revistas.urosario. edu.co/index.php/revsalud/article/viewFile/2026/1782

[40] A. Vivas et al., Evaluación de la mutagenicidad causada por metales pesados presentes en agua del río Cauca en la ciudad de Cali, Colombia. Rev. Colomb. Quim. vol. 42, no. 2. pp. 18-24. Jul. 2014. doi: 10.15446/rev. colomb.quim.v43n2.53119

[41] A. Quijano et al., Potencial mutagénico y genotóxico de aguas residuales de la curtiembre tasajero en la ciudad de Cúcuta, Norte de Santander, Colombia. Rev. Act \& Div. Cien. vol. 18, no. 1, pp. 13-20. Jun. 2015. [En línea] Disponible: http://www.scielo.org. co/pdf/rudca/v18n1/v18nla03.pdf

[42] G. Quintero et al., Efecto genotóxico del agua residual de la curtiembre San Faustino - Norte de Santander - Colombia. Rev. Col. 
de Tec. de Avanzada. vol. 2, no. 32, pp. 8-16. Jun. 2018. [En línea] Disponible: http:// revistas.unipamplona.edu.co/ojs_viceinves/ index.php/RCTA/article/view/3021/1662

[43] D. Chaparro et al., "Un Camino al desarrollo territorial: la especialización en la producción de cebolla de Rama Allium fistulosum en el municipio de Aquitania - Boyacá", Rev. Latinoam. Adm., vol. 8, no. 14,pp. 69-181, May. 2012. [En línea]. Disponible: https://www. researchgate.net/publication/305109696 Un_Camino_al_Desarrollo_Territorial_ la_especializacion_en_la_produccion_de Cebolla_de_Rama_Allium_Fistulosum en_el_municipio_de_Aquitania_-_Boyaca

[44] A. Barrera et al., "Contaminación en el Lago de Tota, Colombia: toxicidad aguda en Daphnia magna (Cladocera: Daphniidae) e Hydra attenuata (Hydroida: Hydridae)", Rev. Bio. Trop., vol. 67, no. 1, pp. 11-23, Mar. 2019, doi: 10.15517/rbt.v67i1.33573

[45] A. Bermúdez et al., "Evaluación del uso y la concentración de Malathion en la cebolla junca en la vereda Quebradas, municipio de Aquitania, y sus posibles efectos adversos sobre la salud," Universidad Santo Tomás, 2015.

[46] A. Pico et al., "Estudio de riesgos químicos inherentes al proceso de cultivo y cosecha de cebolla larga en la vereda Hato viejo del municipio de Aquitania", Universidad Pedagógica y Tecnológica de Colombia, 2016.

[47] A. Mojica et al., "Evaluación del movimiento de plaguicidas hacia la cuenca del Lago de Tota, Colombia", Rev. Colomb. Quim., vol. 42, no. 2, pp. 29-38, Jul. 2013, doi: 10.15446/ rev.colomb.quim

[48] T. Katagi., "Behavior of pesticides in watersediments systems", Rev. Environ. Contam. Toxicol., vol. 187, 133-251, Feb. 2006, doi: 10.1007/0-387-32885-8_4

[49] L. Rojas et al., "Pesticide Flow Analysis in the Tota Lake Watershed in the Boyacá Region in Colombia", en Earth, Geology and Geography abstracts, The atenas institute for education and research. Grecia. 2015, pp. 48-49, 2015.

[50] M. Martínez et al., "Modelación matemática del transporte de oxadixyl en suelos de cultivo de cebolla", Rev. Ambient. Água, vol. 10, no. 2, pp. 227-237, Feb. 2015, [En línea]. Disponible:https://www.scielo.br/ pdf/ambiagua/v10n2/1980-993X-ambiagua-10-02-00327.pdf

[51] IRET, "Manual de plaguicidas de centroamérica" [online]. Costa Rica: Universidad Nacional de Costa Rica, 2020. Disponible en: http://www.plaguicidasdecentroamerica. una.ac.cr/

[52] B. McCluskey et al., "Zebrafish Taxonomy and Phylogeny or Taxonomy and Phylogeny: Biology, Husbandry, Diseases, and Research Applications", en The Zebrafish in Biomedical Research, American College of Laboratory Animal Medicine Series, Elsevier. London. 2020. pp. 15-24. doi: doi. org/10.1016/B978-0-12-812431-4.00002-6

[53] A. Quelle et al., "Estudio experimental de las conexiones tectales y cerebrales en el pez cebra Danio rerio", Universidad de la Coruña, 2014.

[54] M. Martín., "Empleo del pez cebra (Danio rerio) como modelo de estudios de neoplasia", Universidad de Santiago de Compostela, 2019.

[55] M. Fernández, "Aplicación de nuevas herramientas biotecnológicas en la línea germinal del pez cebra (Danio rerio)", Universidad de León, 2013.

[56] M. Mimeault et al., "Emergence of zebrafish models in oncology for validating novel anticancer drug targets and nanomaterials", Rev. Drug. Discov. Today, vol. 18, no. 3-4, pp. 128-140, Feb. 2013, doi: 10.1016 / j.drudis.2012.08.002

[57] K. Bambino et al., "Zebrafish in Toxicology and Environmental Health", Rev. Curr. Top. Dev. Biol., vol. 124, no. 2, pp. 331367, Dic. 2017, doi: doi.org/10.1016/ bs.ctdb.2016.10.007

[58] S. Solis. "Alteraciones en el desarrollo embrionario del pez cebra por exposición a muestras del río Atoyac y descargas industriales". Universidad Nacional Autónoma de México, 2013

[59] A. Armengol, "El pez cebra como modelo de investigación biomédica", Instituto de Oncología Vall d' Hebron, 2017. 
Diego F. Jaramillo-García - Natalia Rodríguez-Sosa - Marleny Salazar-Salazar Carlos A. Hurtado-Montaño - Milena Rondón-Lagos

[60] S. Zhao et al., "A fresh look at zebrafish from the perspective of cancer research", Rev. Exp. Clin. Cancer Res., vol. 34, no. 80, pp. 2-9, Ago. 2015, doi: 10.1186/s13046-015-0196-8

[61] R. Vargas., "Pez cebra (Danio rerio) y anestesia. Un modelo animal alternativo para realizar investigación biomédica básica", Rev. Anest. en México, vol. 29, no. 1, p. 8696, 2017, [En línea]. Disponible: http://www. scielo.org.mx/pdf/am/v29s1/2448-8771am-29-00086.pdf

[62] B. García et al., "Efecto del neonicotinoidetiametoxam en el desarrollo embrionario del pezcebra Daniorerio", Rev. Toxicol.vol35,pp. $22-27,2018$. [En línea] Disponible: ev.aetox. es/wp/wp-content/uploads/2018/06/Revistade-Toxicologia-35.1-26-31.pdf

[63] E. Santidrián, "Toxicidad de nanotransportadores basados en ácido hialurónico en embriones de pez cebra", Universidad de Coruña, 2014.

[64] J. Spitsbergen et al., "The State of the Art of the Zebrafish Model for Toxicology and Toxicologic Pathology Research-Advantages and Current Limitations", Rev. Toxicologic Pathology, vol. 31, pp. 62-87, Ene. 2003, doi: doi.org/10.1080/01926230390174959

[65] L. Rocco et al., "Genotoxicity in Zebrafish (Danio rerio) Exposed to two Pharmacological Products from an Impacted Italian River", Rev. Environment Analityc. Toxicol., vol. 1, no. 2, pp. 1-7, Ago. 2015, doi: doi. org/10.4172/2161-0525.1000103

[66] M. Tye et al., "Dietary contaminants and their effects on Zebrafish Embryos", Rev. Toxics., vol. 7, no. 3, pp. 46, Ago. 2019, doi: doi.org/10.3390/toxics7030046

[67] M. Pandey et al., "Evaluation of cytotoxicity and genotoxicity of insecticide carbaryl to flounder gill cells and its teratogenicity to zebrafish embryos", Rev. Ocean University of China., vol. 14, no. 2, pp. 362-274, Feb. 2015, doi: doi.org/10.1007/s11802-015-2433-3.

[68] S. Cambier et al., "Cadmium-induced genotoxicity in zebrafish at environmentally relevant doses", Rev. Ecotoxicology and Environmental Safety, vol. 73, no. 3, pp. 312-219, Mar. 2010, doi: doi.org/10.1016/j. ecoenv.2009.10.012
[69] O. Báez et al., "Bioacumulación y daños genotóxicos en pez cebra (Danio rerio) por Arsénico en aguas de Zimapán, Hidalgo (México) ensayos en corto plazo", Rev. AquaTIC., vol. 21, p. 62-70, 2004, [En línea]. Disponible: http://www.revistaaquatic.com/ojs/index. php/aquatic/article/view/238/226

[70] C. Álvarez, "Efectos teratogénicos del Nitrato de Plomo en el desarrollo embrionario del pez cebra Danio rerio", Pontificia Universidad Javeriana, 2011.

[71] L. de Brito Rodrigues et al., "Ecotoxicological assessment of glyphosate-based herbicides: Effects on different organisms", Rev. Env. Toxicology and Chemistry., vol. 36, no. 7, pp. 1755-1763, Ago. 2017, doi: doi. org/10.1002/etc. 3580

[72] F. Watson et al., "Organophosphate pesticides induce morphological abnormalities and decrease locomotor activity and heart rate in Danio rerio and Xenopus laevis", Rev. Env. Toxicology and Chemistry, vol. 33, no. 6, pp. 1337-1345, Feb. 2014, doi: doi.org/10.1002/ etc. 2559

[73] J. Sun et al., "Genotoxicity and cytotoxicity reduction of the polluted urban river after ecological restoration: a field-scale study of Jialu River in northern China", Rev. Env. Science and Pollution Research., vol. 24, no. 7, pp. 6715-6723, Ene. 2017, doi: doi. org/10.1007/s11356-016-8352-z

[74] Q. Li et al., "Embryotoxicity and genotoxicity evaluation of sediments from Yangtze River estuary using zebrafish (Danio rerio) embryos", Rev. Environmental Science and Pollution Research., vol. 23, no. 5, pp. 4908-4918, Nov. 2016, doi: doi.org/10.1007/ s11356-015-5737-3

[75] A. D'Costa et al., "Induction of DNA damage in the peripheral blood of zebrafish (Danio rerio) by an agricultural organophosphate pesticide, monocrotophos", Rev. International Aquatic Research., vol. 10, no. 3, pp. 243-251, Ago. 2018, doi: doi.org/10.1007/ s40071-018-0201-x

[76] W. Schmidt et al., "Mixture toxicity of water contaminants-effect analysis using the zebrafish embryo assay (Danio rerio)", Rev. Chemosphere, vol. 152, pp. 503-512, Jun. 2016, doi: 10.1016/j.chemosphere.2016.03.006. 
Carlos A. Hurtado-Montaño - Milena Rondón-Lagos

[77] W. Corredor et al., "Using genotoxic and haematological biomarkers as an evidence of environmental contamination in the Ocoa River native fish, Villavicencio-Meta, Colombia”, Springerplus, vol. 5, no. 1, pp. 351, Dic. 2016, doi: 10.1186/s40064-0161753-0.

[78] M. Raj et al., "Effect of polluted water on Danio rerio (Zebrafish) as a vertebrate model: A case study of Ibalur Lake, Bangalore, India", Rev. South Asian J. Exp Biol, vol. 5, no. 2, pp. 48-54, Ene. 2015. [En línea] Disponible: https://www.researchgate.net/
publication/281627053_Effect_of_polluted_water_on_Danio_rerio_Zebrafish_as_a vertebrate_model_A_case_study_of_Ibalur_Lake_Bangalore_India

[79] O. Arellano et al., "Use of the Zebrafish Embryo Toxicity Test for Risk Assessment Purpose: Case Study", Rev. Fisheriessciences, vol 9, no. 4, pp. 52-62, Sep. 2015. [En línea] Disponible en: https://www.fisheriessciences. com/abstract/use-of-the-zebrafish-embryotoxicity-test-for-risk-assessment-purposecase-study-8192.html 
